\title{
Procalcitonin and C-Reactive Protein in Umbilical Cord Blood as Markers for Early Suspicion of Infection in Newborns of Women with Prenatal Urinary Tract Infection
}

\author{
Rafael Del Castilho Villalba ${ }^{1}$; Adriana Cersósimo ${ }^{1}$; Israel Figueiredo Junior ${ }^{1}$; \\ Adauto Dutra Moraes Barbosa ${ }^{1}$. \\ ${ }^{I}$ (Mother and Child Department, Division of Neonatology, Faculty Of Medicine, Fluminense Federal \\ University, Niterói - Rio De Janeiro; Brazil)
}

\begin{abstract}
:
Objective: to investigate whether concentrations of procalcitonin (PCT) and C-reactive protein (CRP) in the umbilical cord blood $(U C B)$ are valid biomarkers for the detection of infection in newborns of pregnant women with urinary tract infection (UTI). Methods: PCT and CRP were measured from UCB and were verified through a prospective study of newborns with appropriate birth weights, without asphyxia or signs of bacterial infection whose mothers were diagnosed with untreated or inadequately treated UTI during the final trimester of pregnancy. The blood of newborns was analyzed according to Rodwell criteria. Was calculated the relative risk to detect altered PCT and/or CRP concentration in UCB in newborn with positive Rodwell criteria. Results: samples from 97 newborns at term were analyzed according to Rodwell criteria. Fifty-six of them showed negative criteria. The RR was $2.0(95 \% C I-1.1-3.6 p=0.03)$ according to PCT and $2.3(95 \% C I-1.1-4.9) p$ $=0.03$ according to CRP. Conclusion: A normal value to PCT or CRP available from UCB duplicate the possibility to Rodwell negative criteria result in peripheral blood of the neonate, away from the possibility of infection in newborn infants of mothers who had UTI in the pregnancy.
\end{abstract}

Keywords : Procalcitonin, C-reactive protein, urinary tract infection, pregnancy, umbilical cord blood, newborn infection.

\section{Introduction}

Maternal urinary tract infection in the prenatal period is considered a risk factor for the occurrence of intra-amniotic infection, hypertension/preeclampsia, maternal anemia, premature labor, and low birth weight, highlighting the importance of urine examination antepartum [1,2]. McGrady et al. observed that acute urinary tract infection during pregnancy was associated with fetal mortality in $17.9 \%$ of live births, and that early neonatal sepsis onset was of major concern [3]. Due to the lack of sufficiently sensitive or specific criteria for the early detection of neonatal sepsis, neonatologists predict clinical outcome based on the presence of riskfactors and nonspecific test results, before the clinical signs onset. Procalcitonin (PCT) is recognized as a potential early sepsis biomarker [4-8]. During the course of sepsis, PCT is produced by extra-thyroid tissues stimulated by endotoxin and inflammatory cytokines. PCT increases earlier in relation to C-reactive protein (CRP), but its induction is slower than the pro-inflammatory cytokines. The half-life and serum/plasma stability of PCT make it an easy parameter/target for routine use when compared to the inflammatory cytokines [9]. CRP is also an acute-phase protein synthesized by the liver and released after the initiation of the inflammatory process or when tissue is damaged. Serum levels increase after the stimulation of various cytokines such as TNF and interleukin-6. Some studies suggest that CRP could be a marker of infection or sepsis [10, 11].

The purpose of this study was to investigate whether the concentrations of PCT and CRP in the umbilical cord blood are valid as early and specific markers of early neonatal bacterial infection in newborns of pregnant women with untreated or inadequately treated urinary infection during the final trimester of pregnancy.

\section{Methods}

From January 2009 to December 2012 a prospective and cross-sectional study was carried out in a public maternity hospital in Niterói, Rio de Janeiro, Brazil, when 97 newborns were consecutively selected from mothers with third trimester gestational urinary tract infection. This study was approved by the Committee of Ethical Research of Fluminense Federal University (CEP 0010.0.258.000-08), Niterói, Rio de Janeiro. (http://portal2.saude.gov.br/sisnep/pesquisador/extrato_projeto.cfm?codigo=179533)

In order to participate in the research pregnant women should arrive at the hospital with a clinical diagnosis which triggered the maternal screening for urinary tract infection. Urinary infection was considered when patient reported urinary complaints during the prenatal stage and an altered routine examination of urinary sediments confirmed by a positive culture. Mothers who had a history of membranes ruptured for more than 18 
hours, signs of intra-amniotic infection or another known infection, as well as those taking antibiotics were excluded from this study. Those who had not signed a consent form and had incomplete data conditions were also excluded.

Umbilical cord blood for PCT and CRP determination was collected immediately after ligation and section and the material was stored at $-80^{\circ} \mathrm{C}$ to be measurements were made by a semi-quantitative immune chromatographic test (PCT-Q; BRAHMS, Hennigsdorf, Germany). The cut-off values considered were those standardized by their respective manufacturers. PCT concentration was considered normal if the value was equal or less than $0.05 \mathrm{ng} / \mathrm{dl}$. CRP detection, by Latex-Agglutination-Test (Labtest Diagnóstica ${ }^{\circledR}$ ), was considered normal if the value was equal or less than $0.07 \mathrm{mg} / \mathrm{dl}$.

Those newborns from pregnant women with untreated or inadequately treated urinary infection during the final trimester of pregnancy were labeled as presumed sepsis and had peripheral blood analyzed according to the Rodwell hematologic scoring system criteria [12]. According to this system it was considered positive criteria three or more findings (was formulated that assigns a score of one for each of seven findings): abnormal total leukocyte count, abnormal total neutrophil (PMN) count, elevated immature PMN count, elevated immature to total PMN ratio, immature to mature PMN ratio greater than or equal to 0.3, platelet count less than or equal to $150,000 / \mathrm{mm}^{3}$, and pronounced degenerative changes in PMNs. It was considered negative criteria a score less than or equal to two when the probability of sepsis absent was of $99 \%$ [12]. All babies with negative criteria were not considered with sepsis and did not receive antibiotic therapy. Infants with severe asphyxia, respiratory failure and intracranial hemorrhage were also excluded from the study.

Data were analyzed by SPSS ${ }^{\circledR} 16.0$ software (SPSS Inc, Chicago). Results are given as means, standard deviation (SD) and 95\% confidence interval (CI) for mean. Student's t test was used to compare the means among the variables of birth weight, gestational age and Apgar score from $1^{\text {st }}$ to $5^{\text {th }}$ minutes. We also calculated the relative risk between peripheral blood analyzed by Rodwell criteria and cord blood PCT or CPR value.

\section{Results}

All newborns had similar profiles (Table 1). Fifty-six (58\%) newborns from 97 women showed altered blood according to Rodwell criteria for early diagnosis of neonatal sepsis regarding this hematologic scoring system, with normal PCT dosage in $52 \%$ of them. Forty-one newborns with negative criteria, $76 \%$ had normal PCT dosage $(\mathrm{RR}=2.0)$ different from normal CRP, and in $83 \%$ of newborns the criteria was negative $(\mathrm{RR}=$ 2.3) (Table 2).

There were no deaths and all left the hospital in good clinical condition.

\begin{tabular}{|c|c|c|c|c|c|c|c|c|}
\hline & \multicolumn{3}{|c|}{$\begin{array}{l}\text { Rodwell positive criteria } \\
(\mathrm{n}=56)\end{array}$} & \multicolumn{3}{|c|}{$\begin{array}{l}\text { Rodwell negative criteria } \\
(\mathrm{n}=41)\end{array}$} & \multirow[b]{2}{*}{$t$} & \multirow[b]{2}{*}{$P$} \\
\hline & Mean & SD & $95 \% \mathrm{CI}$ & Mean & SD & $95 \% \mathrm{CI}$ & & \\
\hline Birth weight (g) & 3317.0 & 523.9 & $\begin{array}{c}3168.1- \\
3465.9 \\
\end{array}$ & 3318.0 & 413.8 & $\begin{array}{c}3196.5- \\
3439.5\end{array}$ & 0.01 & 0.992 \\
\hline Gestational age(wk) & 39.6 & 1.1 & $39.3-39.9$ & 39.5 & 1.2 & $39.1-39.9$ & 0.11 & 0.637 \\
\hline Apgar score $1^{\circ} \mathrm{min}$ & 8.6 & 0.7 & $8.4-8.8$ & 8.2 & 1.6 & $7,7-8.6$ & $\begin{array}{c}- \\
1.67\end{array}$ & 0.099 \\
\hline Apgar score $5^{\circ} \mathrm{min}$ & 9.18 & 0.4 & $9.0-9.3$ & 9.0 & 0.8 & $8.8-9.3$ & $\overline{-}-\overline{93}$ & 0.357 \\
\hline
\end{tabular}

\begin{tabular}{|l|c|l|l|l|}
\hline \multicolumn{2}{|c|}{ Table 2: PCT and CRP cord blood level vs peripheral blood Rodwell criteria (from baby) } \\
\hline & \multicolumn{2}{|c|}{$\mathrm{PCT}$} & \multicolumn{2}{c|}{ CRP } \\
\hline & $\geq 0.05 \mathrm{ng} / \mathrm{dL}^{1}$ & $<0.05 \mathrm{mg} / \mathrm{dL}^{1}$ & $\geq 0.07 \mathrm{mg} / \mathrm{dL}^{2}$ & $<0.07 \mathrm{mg} / \mathrm{dL}^{2}$ \\
\hline Rodwell positive criteria $(\mathrm{n}=56)$ & $27(48 \%)$ & $29(52 \%)$ & $22(39 \%)$ & $34(61 \%)$ \\
\hline $\begin{array}{l}\text { Rodwell negative criteria } \\
(\mathrm{n}=41)\end{array}$ & $10(24 \%)$ & $31(76 \%)$ & $7(17 \%)$ & $34(83 \%)$ \\
\hline $\mathrm{RR}^{1}=2.0(95 \% \mathrm{CI}-1.1-3.6) \mathrm{z}=2.2 \mathrm{p}=0.03$ & & \\
$\mathrm{RR}^{2}=2.3(95 \% \mathrm{CI}-1.1-4.9) \mathrm{z}=2.2 \mathrm{p}=0.03$ & & \\
\hline
\end{tabular}

\section{Discussion}

In our maternity, all babies from mothers with prenatal urinary tract infection are traced with blood culture, CRP dosage, and peripheral blood examination according to Rodwell criteria evaluation that, if not positive, a new blood sample is collected after 12 hours for other peripheral blood evaluation to some criteria. Then, biomarkers utilization is a great economy in the costs involved in the accomplishment of the complementary examinations, contributing to the reduction of a definitive diagnosis time and fast treatment. Delay in diagnosis and initiation of antibiotics have been shown to increase mortality in cohort studies $[13,14]$. Additionally, a timely diagnosis could also avoid the antibiotic use in cases without evidence of bacterial infection, decreasing the potential development of antimicrobial resistance. 
Several studies involving sepsis, urinary tract infection, central nervous system infection in children and adults utilizing PCT and CRP as biomarkers were published [15-17], but did not describe urinary infection as a frequent problem during pregnancy. If the infection is not properly treated the newborn must be screened for serial blood tests, as well as blood and cerebrospinal cultures to guide the treatment [18].

\section{Conclusion}

A normal value to PCT or CRP available from blood cord duplicate the possibility to Rodwell negative criteria result, avoiding to collect peripheral blood of the newborn from women with urinary tract infection no treated during the pregnancy.

\section{References}

[1]. Schieve LA, Handler A, Hershow R, Persky V and Davis F. Urinary tract infection during pregnancy: its association with maternal morbidity and perinatal outcome. Am J Public Health, 84(3), 1994, 405-410.

[2]. Lee AC, Quaiyum MA, Mullany LC, Mitra DK, Labrique A and Ahmed P, et al. Screening and treatment of maternal genitourinary tract infections in early pregnancy to prevent preterm birth in rural Sylhet, Bangladesh: a cluster randomized trial. BMC Pregnancy Childbirth, 15, 2015, 326.

[3]. Park IH, Lee SH, Yu ST and Oh YK. Serum procalcitonin as a diagnostic marker of neonatal sepsis. Korean J Pediatr, 57(10), 2014, 451-6.

[4]. Chiesa C, Pellegrini G, Panero A, Osborn JF, Signore F and Assumma M, et al. C-reactive protein, interleukin-6, and procalcitonin in the immediate postnatal period: influence of illness severity, risk status, antenatal and perinatal complications, and infection. Clin Chem, 49(1), 2003, 60-68.

[5]. Naher B, Mannan M, Noor K and Shahiddullah M. Role of serum procalcitonin and C-reactive protein in the diagnosis of neonatal sepsis. Bangladesh Med Res Counc Bull, 37(2), 2011, 40-46.

[6]. Hedegaard SS, Wisborg K and Hvas AM. Diagnostic utility of biomarkers for neonatal sepsis - a systematic review. Infect Dis (Lond), 47(3), 2015, 117-124.

[7]. Nargis W, Ibrahim M and Ahamed BU. Procalcitonin versus C-reactive protein: Usefulness as biomarker of sepsis in ICU patient. Int J Crit Illn Inj Sci, 4(3), 2014, 195-199.

[8]. Perez Solis D, Lopez Sastre JB, Coto Cotallo GD, Dieguez Junquera MA, Deschamps Mosquera EM and Crespo Hernandez M. [Procalcitonin for the diagnosis of nosocomial neonatal sepsis]. An Pediatr (Barc), 64(4), 2006, 349-353.

[9]. Meisner M, Tschaikowsky K, Schnabel S, Schmidt J, Katalinic A and Schuttler J. Procalcitonin-influence of temperature, storage, anticoagulation and arterial or venous asservation of blood samples on procalcitonin concentrations. Eur $\mathrm{J}$ Clin Chem Clin Biochem, 35(8), 1997, 597-601.

[10]. Verboon-Maciolek MA, Thijsen SF, Hemels MA, Menses M, van Loon AM and Krediet TG, et al. Inflammatory mediators for the diagnosis and treatment of sepsis in early infancy. Pediatr Res, 59(3), 2006, 457-461.

[11]. Baruti Gafurri Z, Pacarizi H, Zhubi B, Begolli L and Topciu V. The importance of determining procalcitonin and C reactive protein in different stages of sepsis. Bosn J Basic Med Sci, 10(1), 2010, 60-64.

[12]. Rodwell R, Leslie A, Tudehope D. Early diagnosis of neonatal sepsis using a hematologic scoring system. J Pediatr , 112(5), 1988, 761-767.

[13]. Kibe S, Adams K and Barlow G. Diagnostic and prognostic biomarkers of sepsis in critical care. Antimicrob Chemother, 66 (suppl 2), 2011, ii33-ii40

[14]. Cheung Ng P, Ang IL, Chiu RWK, Li K, Lam HS and Wong RPO, et al. Host-response biomarkers for diagnosis of late-onset septicemia and necrotizing enterocolitis in preterm infants. J Clin Invest, 120(8), 2010, 2989-3000.

[15]. Alain G. Usefulness of procalcitonin and C-reactive protein rapid tests for the management of children with urinary tract infection. Pediatr Infect Dis J, 20(5), 2001, 507-511.

[16]. Korczowski B, Szybist W. Serum procalcitonin and C-reactive protein in children with diarrhoea of various aetiologies Acta Paediatr, 93(2), 2004, 169-173.

[17]. Silva M, Amendola C, Longui S, Silva J, Campos E, Rezende E. Procalcitonin in a semi-quantitative test and C-reactive protein in the evaluation of postoperative patients admitted to a critical care unit. Critical Care, 9(P68), 2005, S26-S7.

[18]. Chirico G, Loda C. Laboratory aid to the diagnosis and therapy of infection in the neonate. Pediatr Rep 3, 2011 , e1. 